\title{
Characterizing the type and location of intracranial abnormalities in mild traumatic brain injury
}

\author{
Harri Isokuortti, MD, ${ }^{1}$ Grant L. Iverson, PhD, ${ }^{2,6-8}$ Noah D. Silverberg, PhD, ${ }^{2,3,8,9}$ Anneli Kataja, MD, ${ }^{4}$ \\ Antti Brander, MD, PhD, ${ }^{4}$ Juha Öhman, MD, PhD, ${ }^{5}$ and Teemu M. Luoto, MD, PhD ${ }^{5}$ \\ ${ }^{1}$ Faculty of Medicine and Life Sciences, University of Tampere; ${ }^{4}$ Medical Imaging Centre, Department of Radiology, and \\ ${ }^{5}$ Department of Neurosurgery, Tampere University Hospital, Tampere, Finland; ${ }^{2}$ Department of Physical Medicine and \\ Rehabilitation, Harvard Medical School; ${ }^{6}$ Spaulding Rehabilitation Hospital; ${ }^{7}$ Sports Concussion Program, MassGeneral Hospital \\ for Children; and ${ }^{8} \mathrm{Home}$ Base, A Red Sox Foundation and Massachusetts General Hospital Program, Boston, Massachusetts; \\ ${ }^{3}$ Department of Medicine, Division of Physical Medicine and Rehabilitation, University of British Columbia; and ${ }^{9} \mathrm{GF}$ Strong \\ Rehab Centre, Vancouver, British Columbia, Canada
}

OBJECTIVE The incidence of intracranial abnormalities after mild traumatic brain injury (TBI) varies widely across studies. This study describes the characteristics of intracranial abnormalities (acute/preexisting) in a large representative sample of head-injured patients who underwent $\mathrm{CT}$ imaging in an emergency department.

METHODS CT scans were systematically analyzed/coded in the TBI Common Data Elements framework. Logistic regression modeling was used to quantify risk factors for traumatic intracranial abnormalities in patients with mild TBIs. This cohort included all patients who were treated at the emergency department of the Tampere University Hospital (between 2010 and 2012) and who had undergone head CT imaging after suffering a suspected TBI $(n=3023)$, including 2766 with mild TBI and a reference group with moderate to severe TBI.

RESULTS The most common traumatic lesions seen on CT scans obtained in patients with mild TBIs and those with moderate to severe TBIs were subdural hematomas, subarachnoid hemorrhages, and contusions. Every sixth patient (16.1\%) with mild TBI had an intracranial lesion compared with 5 of 6 patients (85.6\%) in the group with moderate to severe TBI. The distribution of different types of acute traumatic lesions was similar among mild and moderate/severe TBI groups. Preexisting brain lesions were a more common CT finding among patients with mild TBIs than those with moderate to severe TBls. Having a past traumatic lesion was associated with increased risk for an acute traumatic lesion but neurodegenerative and ischemic lesions were not. A lower Glasgow Coma Scale score, male sex, older age, falls, and chronic alcohol abuse were associated with higher risk of acute intracranial lesion in patients with mild TBI.

CONCLUSIONS These findings underscore the heterogeneity of neuropathology associated with the mild TBI classification. Preexisting brain lesions are common in patients with mild TBI, and the incidence of preexisting lesions increases with age. Acute traumatic lesions are fairly common in patients with mild TBI; every sixth patient had a positive CT scan. Older adults (especially men) who fall represent a susceptible group for acute CT-positive TBI.

https://thejns.org/doi/abs/10.3171/2017.7.JNS17615

KEY WORDS traumatic brain injury; head injury; computed tomography; neurodegenerative diseases; common data elements; trauma

$\mathrm{M}$ ILD traumatic brain injuries (MTBIs) are common in sports, ${ }^{9}$ daily life, ${ }^{15}$ and military service. ${ }^{18}$ The "mild" classification is delineated from more severe forms of TBI by a loss of consciousness (LOC) $\leq 30$ minutes, a Glasgow Coma Scale (GCS) score $\geq 13$, and posttraumatic amnesia (PTA) not exceeding 24 hours. MTBIs occur on a broad spectrum-from extremely mild injuries in sports from which an athlete seems to recover within hours or days, to a high-velocity injury in a motor vehicle collision that abuts the moderate TBI severity range. The MTBI classification includes patients with a traumarelated macroscopic intracranial abnormality on a day-ofinjury CT scan, such as an epidural hematoma, subdural hematoma, or contusion, as long as the operational criteria for mild injury are met based on LOC, GCS score, and PTA. This subgroup with acute traumatic intracranial abnormalities has been termed a "complicated" MTBI ${ }^{63}$ As a group, patients with complicated MTBIs are more likely to

ABBREVIATIONS CDE = Common Data Element; DAI = diffuse axonal injury; ED = emergency department; GCS = Glasgow Coma Scale; LOC = loss of consciousness; MTBI = mild traumatic brain injury; PTA = posttraumatic amnesia; WHO = World Health Organization.

SUBMITTED March 15, 2017. ACCEPTED July 6, 2017.

INCLUDE WHEN CITING Published online January 12, 2018; DOI: 10.3171/2017.7.JNS17615. 
have early cognitive deficits ${ }^{2,23,29,63}$ and worse medium- ${ }^{62,63}$ and long-term ${ }^{58}$ functional outcomes. However, there have been studies that have not found worse outcomes. ${ }^{24,31,37,43}$

The incidence of acute CT-positive intracranial lesions in patients with MTBI varies widely between $4.7 \%$ and $38.9 \%$ across individual studies. ${ }^{25,54}$ The wide range in incidence is partially explained by varying enrollment of patients with lower GCS scores, because GCS scores < 15 are associated with an increased risk for intracranial injury. ${ }^{42}$ For those with GCS scores in the mild range (that is, 13-15), each 1-point drop in GCS score is associated with a substantially increased rate of intracranial abnormalities. ${ }^{61}$ Epidural hematomas, focal contusions, subarachnoid hemorrhages, and subdural hematomas are the most common CT-positive lesions seen in patients with moderate to severe TBI. ${ }^{36,45}$

The frequency is lower but the distribution seems similar in patients with MTBI. ${ }^{17,55}$ In those who have sustained MTBIs, only approximately $1 \%$ of lesions require acute neurosurgery. ${ }^{21,52,55}$ Certain patient and injury factors have been associated with increased risk of trauma-related intracranial abnormalities after sustaining an MTBI, including older age, ${ }^{47}$ preexisting medical conditions such coagulopathy, ${ }^{26,40}$ alcohol intoxication at the time of injury, ${ }^{12,17}$ lower GCS score (that is, 13 or 14 vs 15 ), ${ }^{61}$ and dangerous causes of injury such as motor vehicle accidents and falls from a height. ${ }^{55}$ The effects of other characteristics such as neurodegenerative diseases, brain atrophy, or chronic alcohol abuse on risk for traumatic intracranial lesions are not well known. In addition, the relative strength of association of characteristics such as age and cause of injury with CT findings is not well understood.

To systematically document and control for heterogeneity in TBI clinical trials, neuroimaging Common Data Elements (CDEs) were developed for TBI. ${ }^{10,16}$ The motivation for creating a CDE database was to enable the eventual characterization of the natural history and predictive factors in TBI. The structure of a CDE set for neuroimaging has implications for how patients entering clinical trials will be classified, stratified, and treated. To our knowledge, no study has described in detail the intracranial abnormalities after MTBI according to the CDEs.

The primary aim of this study was to describe the type and location of intracranial abnormalities (both acute and preexisting lesions) in a large generalizable inception cohort $(n=3023)$ of patients who sustained head trauma and underwent CT scanning in an emergency department (ED), providing incidence rates for the TBI neuroimaging CDEs. Secondary aims were to 1) compare and contrast the CT abnormalities in MTBI versus moderate to severe TBI, 2) investigate the association between preexisting and acute CT lesions, and 3) investigate the impact of common preinjury factors (such as age and alcohol abuse) on the incidence of acute intracranial lesions.

\section{Methods}

The patient pool for this study included all consecutive patients who were treated at the ED of the Tampere University Hospital between August 2010 and July 2012 and who underwent head CT after a suspected TBI ( $\mathrm{n}=$
3023; age range $0.3-103.8$ years). The ED provides health services for a joint municipal authority of 22 municipalities (both urban and rural), with a catchment area of approximately 470,000 residents. The Tampere University Hospital is the second-largest trauma center in Finland and the only neurosurgical referral center in the area. Each year, the ED of Tampere University Hospital treats approximately 3000 patients with head injury. This includes everything from a bump to the head to severe surgically treated TBI. Approximately 6000 patients with head injury were treated during the data collection period. Ethics approval for the study was obtained from the Ethics Committee of Pirkanmaa Hospital District, Tampere, Finland.

Data were extracted retrospectively from hospital records. Participant-related data included age, sex, substance abuse, and diagnosed diseases. The data on preexisting and comorbid conditions were extracted from the hospital records related to the index injury and all available medical history from the records; no additional diagnostic testing was performed. Chronic alcohol abuse was defined according to codes F10.1 and F10.2 of the International Classification of Diseases, Tenth Revision. Injury-related variables included time of injury, time of arrival to the ED, cause of injury, and alcohol (breathalyzer and/or blood alcohol level) and/or narcotics intoxication at the time of injury. The cause of injury was categorized. Clinical variables related to TBI included eye-witnessed LOC, seizures, disorientation, PTA, and focal neurological deficits. The on-call ED physician identified amnesia by conducting an open interview regarding pre- and postinjury events. Only the presence or absence of amnesia was coded; the duration of amnesia was usually not noted in the records. No structured forms or standardized measures for amnesia were used.

We used the World Health Organization (WHO) definition of MTBI. ${ }^{3}$ Based on the chart review, we grouped patients into 3 categories according to their injury severity: 1) patients with head injury who were triaged to undergo head CT scanning but had missing data in their medical records relating to TBI severity indicators (these cases are called "suspected MTBI" hereafter), 2) patients who met WHO criteria for MTBI based on the details documented in their medical records ("confirmed MTBI"), and 3) patients with moderate to severe TBI (more severe TBI than defined by the WHO criteria, that is, GCS score $<13$, LOC $>30$ minutes, or PTA $>24$ hours). When the chart review revealed evidence that the GCS score was probably lowered by non-brain injury factors $(n=92)$, TBI severity classification was made on the basis of LOC and PTA. This is consistent with WHO criteria, which state that "These manifestations of MTBI must not be due to drugs, alcohol, medications, caused by other injuries or treatment for other injuries." 19 The GCS score obtained 30 minutes postinjury or upon presentation to the ED (whichever came later) was used in the present analyses.

In the ED, a noncontrast head $\mathrm{CT}$ was performed with a 64-row CT scanner (GE, LightSpeed VCT) for all consecutive patients with a head injury. Referral criteria for acute head CT were based on the 2000 Scandinavian guidelines for initial management of minimal, mild, and moderate head injuries. ${ }^{22}$ Head CT was performed in the ED within 72 hours of injury. All CT scans were analyzed and sys- 
tematically coded by 2 neuroradiologists (A.B. and A.K.) using a structured and detailed case report form designed for this study. CT findings were defined as acute or preexisting. Acute lesions included subdural hemorrhage and effusion, epidural hemorrhage and effusion, diffuse axonal injury (DAI) lesions, edema, compression of the CSF spaces, midline shift, contusions, hydrocephalus, pneumocephalus, skull and facial bone fractures, subarachnoid hemorrhage, nontraumatic intracranial hemorrhage, and acute ischemia. Preexisting findings included ischemic lesions, posttraumatic lesions, microangiopathy/small-vessel ischemic disease, general atrophy, and intracranial tumors. Preexisting small-vessel disease was considered if either periventricular or subcortical patchy low-density areas in cerebral white matter were found and compared with normal brain parenchyma with no mass effect. Study data were collected before the CDEs for TBI imaging were established. However, all CDEs possible with noncontrast structural CT scan were included. ${ }^{16}$

MTBI and moderate to severe TBI groups, as well as subgroups with versus without acute intracranial abnormalities, were compared using the chi-square test for proportions and t-tests for group mean differences. Unconditional logistic regression modeling was performed to estimate the odds ratios (ORs) and 95\% CIs of acute intracranial abnormalities while controlling for multiple confounders (demographic data, clinical variables, and preexisting imaging features).

\section{Results}

Demographic data and clinical characteristics of the injury severity groups are presented in Table 1 . The rates of trauma-related intracranial abnormalities were $11.6 \%$, $16.1 \%$, and $85.6 \%$ in the suspected and confirmed MTBI group, confirmed MTBI subgroup, and moderate to severe TBI group, respectively. All of the acute lesions in the suspected and confirmed MTBI group were from patients in the confirmed MTBI subgroup. Within the suspected and confirmed MTBI group, the percentages of patients with complicated MTBIs stratified by GCS scores were as follows: 15 (10.1\%), 14 (36.1\%), 13 (48.1\%), and 11.5\% in those patients for whom the GCS score was not available. Within the confirmed MTBI subgroup, the percentages of patients with complicated MTBIs stratified by GCS scores were as follows: 15 (14.2\%), 14 (40.7\%), 13 (52.0\%), and $15.2 \%$ in those patients for whom the GCS score was not available. In the total sample, the number of patients and percentages of traumatic intracranial abnormalities, stratified by time between injury and CT scanning, were as follows: 0-2 hours (158 [29.3\%]), 3-6 hours (129 [23.9\%]), 7-11 hours (58 [10.7\%]), 12-23 hours (49 [9.1\%]), 24-47 hours (37 [6.9\%]), and $\geq 48$ hours (109 [20.2\%]).

Specific CT findings stratified by the injury severity groups are presented in Table 2. In the total MTBI group, the incidence of specific abnormalities was as follows: subdural hematoma (8.4\%), subarachnoid hemorrhage (5.0\%), and contusion (3.9\%). Of the 142 contusions (in 109 patients), $52.8 \%$ were frontal and $39.4 \%$ were temporal in location. Of the 495 subdural hematomas (in 232 patients), $38.8 \%$ were frontal, $21.8 \%$ were temporal, $22.0 \%$ were pa- rietal, and only $7.5 \%$ were occipital. In comparison, in the moderate to severe TBI group, the incidence of specific abnormalities was as follows: subdural hematoma (63.0\%), subarachnoid hemorrhage (55.6\%), and contusion (43.6\%). Of the 150 contusions (in 112 patients), 50.0\% were frontal and $40.0 \%$ were temporal in location. Of the 439 subdural hematomas (in 162 patients), $32.1 \%$ were frontal, $24.8 \%$ were temporal, $21.0 \%$ were parietal, and only $9.8 \%$ were occipital.

The total MTBI group included 2766 patients with a suspected or confirmed MTBI. Patients in the subgroup of those with complicated MTBIs were older (mean \pm SD $66.7 \pm 19.9$ years) than those with uncomplicated MTBIs $(53.4 \pm 24.5$ years; $p<0.001)$, and men were significantly more likely to have complicated MTBIs than women $(12.8 \%$ vs $10.1 \%$, chi-square test $4.99, \mathrm{p}=0.026)$. Within the complicated MTBI group, the mechanisms of injury were as follows: motor vehicle accident $(2.2 \%)$, traffic accident as pedestrian or bicyclist $(7.5 \%)$, fall from a height $(10.3 \%)$, and ground-level fall $(66.3 \%)$. Older adults $(\geq 55$ years) who were injured in a ground-level fall had a greater incidence of trauma-related abnormalities than younger adults injured in a fall $(17.0 \%$ vs $5.8 \%$, chi-square test 85.89, $\mathrm{p}<0.001$ ). Rates of complicated MTBIs, stratified by age group, are presented in Fig. 1. Rates of complicated MTBIs increased with age.

The study population included 275 patients who were < 20 years old. Stratified by age, 27 patients were $0-5$ years, 24 were $6-10$ years, 82 were $11-15$ years, and 142 were $16-$ 19 years. Of the 275 patients $<20$ years old, 19 had a traumatic lesion (6.9\%): 6 in the $0-5$ years age group (22.2\%), none in the $6-10$ years age group, 7 in the $11-15$ years age group (8.5\%), and 6 in the 16-19 years age group (4.2\%). The most common lesions were subarachnoid hemorrhages and subdural hematomas. Subarachnoid hemorrhage was found in 8 patients ( 3 in the youngest group, none in the $6-10$ years age group, 1 in the $10-15$ years age group, and 4 in the oldest age group). There were 8 subdural hematomas: 4 in the 11-15 years age group and 4 in the 16-19 years age group. Each of the age groups had more males than females: 18 males in the $0-5$ years age group, 16 males in the $6-10$ years age group, 52 males in the $11-15$ years age group, and 88 males in the 16-19 years age group.

Rates of preexisting abnormalities on CT, stratified by age group, are also presented in Fig. 1. Rates of preexisting lesions increased dramatically with age. In the total MTBI sample, $34.0 \%$ of patients had a preexisting abnormality, and $18.7 \%$ had $>1$ preexisting abnormality. Smallvessel ischemic disease was present in $21.0 \%$ of patients, ischemic lesions in $7.2 \%$, generalized atrophy in $17.9 \%$, and posttraumatic lesions in $2.8 \%$. Among older adults $(\geq$ 55 years), those with $\mathrm{CT}$ evidence of preexisting atrophy were less likely to have a complicated MTBI than those without obvious atrophy $(12.6 \%$ vs $19.0 \%$, chi-square test $8.52, \mathrm{p}=0.004)$. The rate of complicated MTBIs in older adults (age $\geq 55$ years) who had a preexisting neurodegenerative disease was similar to that in those who did not have a neurodegenerative disease $(14.1 \%$ vs $17.6 \%$, chisquare test $1.64, \mathrm{p}=0.200$ ).

In a logistic regression analysis with the total MTBI sample $(n=2766)$, a number of variables were associated 
TABLE 1. Characteristics of the study cohort

\begin{tabular}{|c|c|c|c|}
\hline Variable & Suspected or Confirmed MTBI & Confirmed MTBI & Moderate to Severe TBI \\
\hline No. of patients & 2766 & 1990 & 257 \\
\hline Age, yrs & $56.4(34.2-77.1)$ & $58.4(34.7-77.8)$ & $57.5(40.0-74.9)$ \\
\hline \multicolumn{4}{|l|}{ Time interval, hrs } \\
\hline Injury to ED admission & $4.5(1.4-45.0)$ & $4.5(1.4-40.4)$ & $2.5(1.0-8.9)$ \\
\hline Injury to head CT & $6.5(2.6-47.7)$ & $6.5(2.6-44.8)$ & $4.3(1.8-11.2)$ \\
\hline ED admission to head CT & $1.0(0.6-1.8)$ & $1.0(0.6-1.9)$ & $0.7(0.4-1.2)$ \\
\hline Head CT to discharge & $6.0(2.2-27.6)$ & $6.6(2.3-28.4)$ & $88.1(19.9-196.1)$ \\
\hline Hospital stay & $8.2(3.8-29.1)$ & $9.0(3.9-31.2)$ & $89.5(22.1-197.6)$ \\
\hline \multicolumn{4}{|l|}{ Sex } \\
\hline Male & $1542(55.1)$ & $1131(56.8)$ & $181(70.4)$ \\
\hline Female & $1242(44.9)$ & $859(43.2)$ & $76(29.6)$ \\
\hline CT w/in 24 hrs & $1865(67.4)$ & 1355 (68.1) & $218(84.8)$ \\
\hline CT w/in $48 \mathrm{hrs}$ & $2076(75.1)$ & $1503(75.5)$ & $235(91.4)$ \\
\hline \multicolumn{4}{|l|}{ Cause of injury } \\
\hline Motor vehicle collision & $275(9.9)$ & $200(10.1)$ & $23(8.9)$ \\
\hline Traffic accident as pedestrian or bicyclist & $145(5.2)$ & $118(5.9)$ & $22(8.6)$ \\
\hline Falls from a height & $304(11.0)$ & $216(10.9)$ & $33(12.8)$ \\
\hline Ground-level falls & $1454(52.6)$ & $1087(54.6)$ & $130(50.6)$ \\
\hline Other & $535(19.3)$ & $324(16.3)$ & $29(11.3)$ \\
\hline \multicolumn{4}{|l|}{ Follow-up treatment } \\
\hline Home & $1215(43.9)$ & $813(41.3)$ & $28(7.6)$ \\
\hline Health center & $628(22.7)$ & $489(24.6)$ & $28(10.9)$ \\
\hline Other health care facility & $87(3.1)$ & $68(3.4)$ & $4(1.6)$ \\
\hline Hospital & $809(29.2)$ & $599(30.1)$ & $172(66.9)$ \\
\hline Death & $27(1.0)$ & $17(0.9)$ & $41(16.0)$ \\
\hline \multicolumn{4}{|l|}{ Alcohol intoxication } \\
\hline Yes & $660(23.9)$ & $520(26.1)$ & $81(31.5)$ \\
\hline No & $1151(41.6)$ & $826(41.5)$ & $92(35.8)$ \\
\hline Unknown & $955(34.5)$ & $644(32.4)$ & $84(32.7)$ \\
\hline \multicolumn{4}{|l|}{ LOC } \\
\hline Yes & $481(17.4)$ & $462(23.2)$ & $103(40.1)$ \\
\hline No & $764(27.6)$ & $384(19.3)$ & $25(9.7)$ \\
\hline Not witnessed/unknown & $1521(55.0)$ & $1144(57.5)$ & $129(50.2)$ \\
\hline \multicolumn{4}{|l|}{ Amnesia } \\
\hline Yes & $646(23.4)$ & $637(32.0)$ & $38(14.8)$ \\
\hline No & $916(33.1)$ & $438(22.0)$ & $16(6.2)$ \\
\hline Unknown & $1204(43.5)$ & $915(46.0)$ & $203(79.0)$ \\
\hline \multicolumn{4}{|l|}{ GCS score, points } \\
\hline $13-15$ & $1682(60.8)$ & $1223(61.5)$ & $34(13.2)$ \\
\hline $9-12$ & $67(2.4)$ & $13(0.7)$ & $75(29.2)$ \\
\hline $3-8$ & $25(0.9)$ & $2(0.1)$ & $83(32.3)$ \\
\hline NA & $992(35.9)$ & $752(37.8)$ & $65(25.3)$ \\
\hline \multicolumn{4}{|l|}{ CT } \\
\hline Traumatic intracranial abnormality & $320(11.6)$ & $320(16.1)$ & $220(85.6)$ \\
\hline Preexisting abnormality & $941(34.0)$ & $717(36.0)$ & $44(17.1)$ \\
\hline
\end{tabular}

with a higher rate of acute intracranial lesions. The results of the logistic regression analysis are presented in Table 3 . In the single covariate models (producing unadjusted
ORs), male sex, older age, cause of injury, lower GCS score, chronic alcohol abuse, and preexisting traumatic lesions on CT were significant predictors. 
TABLE 2. Intracranial abnormalities following TBI

\begin{tabular}{|c|c|c|c|}
\hline Variable & Suspected \& Confirmed MTBI & Confirmed MTBI & Moderate to Severe TBI \\
\hline No. of patients & 2766 & 1990 & 257 \\
\hline \multicolumn{4}{|l|}{ Abnormality/location } \\
\hline Epidural hematoma* & $6(0.2)$ & $6(0.3)$ & $15(5.8)$ \\
\hline Subdural hematoma* & $232(8.4)$ & $232(11.7)$ & $162(63.0)$ \\
\hline Frontal & $192(6.9)$ & $192(9.6)$ & $141(54.9)$ \\
\hline Temporal & $108(3.9)$ & $108(5.4)$ & $109(42.4)$ \\
\hline Parietal & $109(3.9)$ & $109(5.5)$ & $92(35.8)$ \\
\hline Occipital & $37(1.3)$ & $37(1.9)$ & $43(16.7)$ \\
\hline Cerebellar & $3(0.1)$ & $3(0.2)$ & $3(1.2)$ \\
\hline Tentorial & $46(1.7)$ & $46(2.3)$ & $51(19.8)$ \\
\hline Subarachnoid hemorrhage* & $139(5.0)$ & $139(7.0)$ & $143(55.6)$ \\
\hline Intraventricular* & $33(1.2)$ & $33(1.7)$ & $53(20.6)$ \\
\hline Basal cisterns & $24(0.9)$ & $24(1.2)$ & $36(14.0)$ \\
\hline Convexity sulci & $113(4.1)$ & $113(5.7)$ & $124(48.2)$ \\
\hline Contusion* & $109(3.9)$ & $109(5.5)$ & $112(43.6)$ \\
\hline Frontal & $75(2.7)$ & $75(3.8)$ & $75(29.2)$ \\
\hline Temporal & $56(2.0)$ & $56(2.8)$ & $60(23.3)$ \\
\hline Parietal & $6(0.2)$ & $6(0.3)$ & $3(1.2)$ \\
\hline Occipital & $1(0.04)$ & $1(0.1)$ & $2(0.8)$ \\
\hline Cerebellar & $2(0.1)$ & $2(0.1)$ & $8(3.1)$ \\
\hline Brainstem & $2(0.1)$ & $2(0.1)$ & $2(0.8)$ \\
\hline $\mathrm{DAl}^{*}$ & $5(0.2)$ & $5(0.3)$ & $9(3.5)$ \\
\hline CSF space compression* & $35(1.3)$ & $35(1.8)$ & 75 (29.2) \\
\hline Ventricles* & $22(0.8)$ & $22(1.1)$ & $58(22.6)$ \\
\hline Basal cisterns* & $5(0.2)$ & $5(0.3)$ & $41(16.0)$ \\
\hline Convexity sulci & $22(0.8)$ & $22(1.1)$ & $61(23.7)$ \\
\hline Fractures & $168(6.1)$ & $142(7.1)$ & $112(43.6)$ \\
\hline Skull fractures* & $76(2.7)$ & $75(3.8)$ & $95(37.0)$ \\
\hline Facial fractures & $103(3.7)$ & $78(3.9)$ & 44 (17.1) \\
\hline Pneumocephalus & $10(0.4)$ & $10(0.5)$ & $20(7.8)$ \\
\hline Hydrocephalus & $8(0.3)$ & $6(0.3)$ & $6(2.3)$ \\
\hline Nontraumatic hemorrhage & $16(0.6)$ & $13(0.7)$ & $16(6.2)$ \\
\hline Acute ischemia* & $24(0.9)$ & $17(0.9)$ & $4(1.6)$ \\
\hline Midline shift* & $45(1.6)$ & $44(2.2)$ & $89(34.6)$ \\
\hline Diffuse edema* & $2(0.1)$ & $1(0.1)$ & $15(5.8)$ \\
\hline \multicolumn{4}{|l|}{ Preexisting abnormalities } \\
\hline Preexisting posttraumatic lesions & $77(2.8)$ & $62(3.1)$ & $5(1.9)$ \\
\hline Preexisting ischemic lesions & $198(7.2)$ & $159(8.0)$ & $6(2.3)$ \\
\hline Microangiopathy/small-vessel ischemic disease & $581(21.0)$ & $441(22.2)$ & $26(10.1)$ \\
\hline Generalized atrophy* & $495(17.9)$ & $377(18.9)$ & $25(9.7)$ \\
\hline Tumors & $21(0.8)$ & $17(0.9)$ & $1(0.4)$ \\
\hline \multicolumn{4}{|l|}{ Summary } \\
\hline Any traumatic intracranial abnormality & $320(11.6)$ & $320(16.1)$ & $220(85.6)$ \\
\hline$>1$ traumatic intracranial abnormality & $128(4.6)$ & $128(6.4)$ & $144(56.0)$ \\
\hline Any preexisting abnormality & $941(34.0)$ & $717(36.0)$ & $44(17.1)$ \\
\hline$>1$ preexisting abnormality & $518(18.7)$ & $400(20.1)$ & $27(10.5)$ \\
\hline Any traumatic intracranial \& preexisting abnormality & $146(5.3)$ & $133(6.7)$ & $37(14.4)$ \\
\hline Any traumatic intracranial or preexisting abnormality & $1212(43.8)$ & $904(45.2)$ & $227(88.3)$ \\
\hline
\end{tabular}

Values are expressed as the number (\%) of patients.

* Pathoanatomical lesions listed within the CDEs. ${ }^{29}$ 


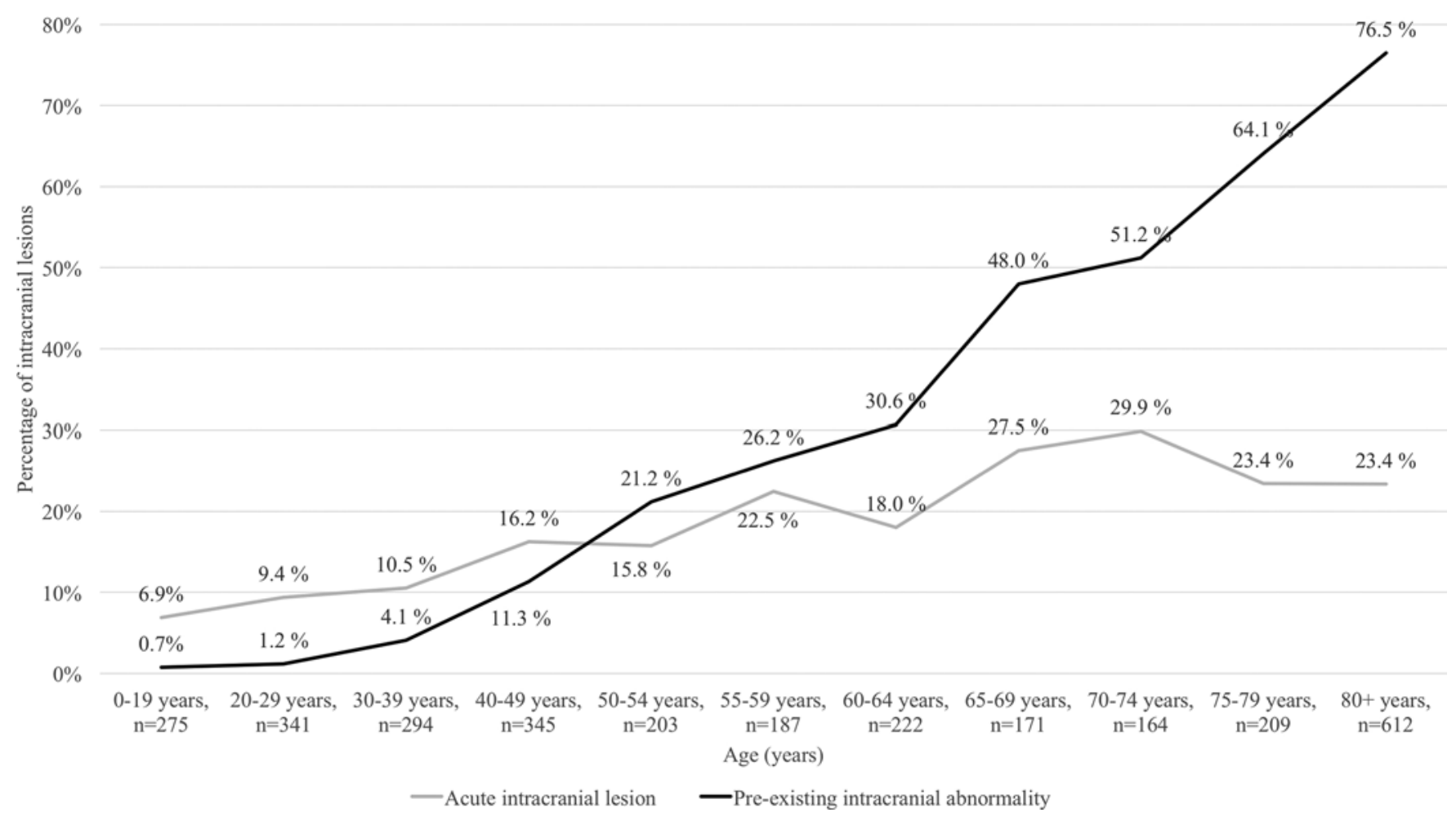

FIG. 1. Graph comparing incidence of intracranial lesions by age in the whole cohort $(n=3023)$. Gray line indicates acute intracranial lesions; black line indicates preexisting intracranial abnormality.

In the multivariable model, significant independent predictors were male sex (OR 1.68, 95\% CI 1.27-2.21), age (OR $1.04,95 \%$ CI $1.03-1.05$ ), having a preexisting traumatic lesion (OR 1.99, 95\% CI 1.12-3.56), chronic alcohol use (OR 1.84, 95\% CI 1.29-2.63), certain mechanisms of injury (being a pedestrian or a bicyclist in a traffic accident [OR 7.54, 95\% CI 3.05-18.65], or falling from a height [OR 4.32, 1.82-10.23], ground-level falls [OR 3.9, 95\% CI 1.75-8.68] vs a motor vehicle accident), and a GCS score of 14 (OR 4.35, 95\% CI 2.69-7.05) or 13 (OR 7.70, 95\% CI $3.26-18.18$ ) versus 15.

Interestingly, cerebral atrophy was associated with significantly lower risk for an acute traumatic intracranial abnormality (OR 0.48, 95\% CI 0.34-0.68). Small-vessel ischemic disease was also associated with lower risk for having a complicated MTBI (OR 0.58, 95\% CI 0.41-0.81). Of note, the multivariable model indicated that age and sustaining an MTBI due to a ground-level fall were independently associated with having a positive head CT scan, suggesting that the high rate of CT abnormalities associated with ground-level falls was not entirely confounded by older adults having more falls than younger adults.

\section{Discussion}

MTBIs vary in terms of mechanisms, pathophysiology, and clinical outcomes. ${ }^{32,35}$ We have provided a detailed description of CT findings in patients with MTBI (with a reference group of patients with moderate to severe TBI) and documented factors associated with $\mathrm{CT}$ abnormalities in patients with MTBI. This study has several strengths. It involved a large unselected sample of patients with head injury who were consecutively treated in an ED. Other than requiring a clinically indicated CT scan of the head, we did not apply eligibility criteria, making the study findings generalizable and enabling us to examine the association between a large number of factors and the incidence of intracranial abnormalities.

Another strength of this study was that traumatic lesions were systematically coded using prespecified CDEs recently developed for TBI research..$^{0,16}$ We also included a comparison group of patients with moderate to severe TBI. A key finding was that a substantial number of patients who sustained an MTBI had traumatic intracranial lesions on head CT, even those without clear documentation of acute clinical signs of MTBI in their ED medical record. No individual historical or physical examination features can completely rule out intracranial injury following minor head trauma. ${ }^{13}$ In our study, $11.6 \%-16.1 \%$ of patients with MTBI had an acute intracranial lesion, which falls within the range of prior studies. . $27,33,41,49,53,54,59^{\mathrm{We}}$ further observed that the type and location of traumatic lesions are similar across the whole severity spectrum of TBI. Subdural hematoma, subarachnoid hemorrhage, and contusions occurring in the frontal and temporal regions are most common in MTBI and more severe TBIs.

It is unclear the extent to which macrostructural lesions help explain the heterogeneity of clinical outcomes from MTBI. Widely variable patterns of pathology may be seen on structural imaging in patients with similar injury severity as assessed by GCS scores..$^{48} \mathrm{~A}$ few prior studies have included CT positive versus negative as a prognostic factor. Some studies have suggested that $\mathrm{CT}$ abnormalities are associated with worse outcome, ${ }^{23,63}$ but some studies have 
TABLE 3. Logistic regression analysis of acute intracranial lesions in 2766 patients with suspected and confirmed MTBI

\begin{tabular}{|c|c|c|c|c|c|c|}
\hline \multirow[b]{2}{*}{ Predictor (no. [\%]) } & \multicolumn{3}{|c|}{ Unadjusted } & \multicolumn{3}{|c|}{ Adjusted } \\
\hline & $\mathrm{p}$ Value & OR & $95 \% \mathrm{Cl}$ & $p$ Value & OR & $95 \% \mathrm{Cl}$ \\
\hline \multicolumn{7}{|l|}{ Sex } \\
\hline Female (1242 [44.9]) & Ref & & & Ref & & \\
\hline Male (1524 [55.1]) & 0.026 & 1.31 & $1.03-1.66$ & $<0.001$ & 1.68 & $1.27-2.21$ \\
\hline Age, yrs & $<0.001$ & 1.03 & $1.02-1.03$ & $<0.001$ & 1.04 & $1.03-1.05$ \\
\hline \multicolumn{7}{|l|}{ Cause of injury } \\
\hline Motor vehicle collision (275 [9.9]) & Ref & & & Ref & & \\
\hline Traffic accident as pedestrian or bicyclist (145 [5.2]) & $<0.001$ & 7.59 & $3.19-18.11$ & $<0.001$ & 7.54 & $3.05-18.65$ \\
\hline Fall from a height (304 [11.0]) & $<0.001$ & 4.66 & $2.03-10.72$ & 0.001 & 4.32 & $1.82-10.23$ \\
\hline Ground-level fall (1454 [52.6]) & $<0.001$ & 6.54 & $3.04-14.04$ & 0.001 & 3.90 & $1.75-8.68$ \\
\hline Other (535 [19.3]) & 0.019 & 2.68 & $1.18-6.12$ & 0.008 & 3.15 & $1.34-7.39$ \\
\hline Unknown (53 [1.9]) & $<0.001$ & 7.83 & $2.77-22.11$ & 0.032 & 3.36 & $1.11-10.21$ \\
\hline \multicolumn{7}{|l|}{ Alcohol use preceding injury } \\
\hline No (1151 [41.6]) & Ref & & & Ref & & \\
\hline Yes (660 [23.9]) & 0.297 & 1.17 & $0.87-1.57$ & 0.559 & 1.12 & $0.76-1.64$ \\
\hline Unknown (955 [34.5]) & 0.625 & 1.07 & $0.82-1.40$ & 0.579 & 1.09 & $0.81-1.46$ \\
\hline Chronic alcohol abuse (488 [17.6]) & $<0.001$ & 1.63 & $1.24-2.15$ & $<0.001$ & 1.84 & $1.29-2.63$ \\
\hline \multicolumn{7}{|l|}{ GCS score } \\
\hline $15(1558$ [56.3]) & Ref & & & Ref & & \\
\hline $14(97[3.5])$ & $<0.001$ & 5.00 & $3.20-7.81$ & $<0.001$ & 4.35 & $2.69-7.05$ \\
\hline $13(27[1.0])$ & $<0.001$ & 8.23 & $3.80-17.82$ & $<0.001$ & 7.70 & $3.26-18.18$ \\
\hline $3-12(92[3.3])^{*}$ & - & - & - & - & - & - \\
\hline Unknown (992 [35.9]) & 0.282 & 1.15 & $0.89-1.49$ & 0.860 & 1.02 & $0.78-1.34$ \\
\hline Small-vessel ischemic disease (581 [21.0]) & 0.154 & 1.22 & $0.93-1.61$ & 0.001 & 0.58 & $0.41-0.81$ \\
\hline Neurodegenerative disease (229 [8.3]) & 0.236 & 1.27 & $0.86-1.88$ & 0.750 & 0.93 & $0.60-1.45$ \\
\hline Preexisting traumatic lesion on CT (77 [2.8]) & $<0.001$ & 3.00 & $1.79-5.02$ & 0.02 & 1.99 & $1.12-3.56$ \\
\hline Cerebral atrophy (495 [17.9]) & 0.967 & 0.99 & $0.73-1.35$ & $<0.001$ & 0.48 & $0.34-0.68$ \\
\hline
\end{tabular}

presented opposite results. ${ }^{56}$ Few studies have examined the relationship between specific CT findings and outcome. ${ }^{65}$ Further research is needed on neuroimaging as a prognostic factor. Consideration of other biopsychosocial factors (e.g., preinjury mental health, sex, personality factors, resilience, and acute postinjury psychological distress) in a multivariate model will be important in prognostic research. ${ }^{4,51}$

Preexisting nontraumatic lesions were common in patients with TBI, but they were not associated with increased risk of sustaining a CT-positive MTBI. Specifically, preexisting, degenerative, and ischemic lesions in the brain did not increase the risk for acute traumatic lesions. Instead, the underlying increased risk for intracranial abnormalities associated with aging may be caused by other comorbidities and antithrombotic medication. Poorer health and functioning predict the occurrence of TBI in elderly persons. ${ }^{8}$ A common belief is that cerebral atrophy is a risk factor for acute and chronic subdural hemorrhage. To our knowledge, only 1 study has suggested that cerebral atrophy may predispose to traumatic intracranial hemorrhage. ${ }^{11}$ In our study, atrophy was not associated with risk for hemorrhage; in fact, the association was the opposite.
Advanced age is a well-known risk factor for an intracranial abnormality in head injury. $7,17,38-40,46,55,57,61$ The present study highlights that older age increases the risk of any CDE intracranial abnormality fairly linearly across adulthood, although such risk may plateau at approximately 60-70 years of age. Falls are the leading cause of TBI among elderly people. $5,7,28,57,60$ The risk of falling could be associated with intrinsic risks that occur with aging (e.g., chronic medical conditions, impaired balance, slower reaction times, decreased muscle strength, impaired cognition, and use of medications that predispose patients to postural hypotension and dizziness).

Similar to previous studies, chronic alcohol abuse increased the risk of having an acute traumatic lesion on head CT. Acute intoxication, however, did not increase the risk of intracranial abnormalities. Alcohol abuse is common before TBI, with a prevalence of $37 \%-51 \% .^{44}$ In our study, $18.4 \%$ of patients had a history of alcohol abuse. Both acute and chronic alcohol abuse may impair decision making, motor control, and inhibitory control..$^{50}$ Binge drinking is the most common pattern of drinking among trauma patients, and the injuries of such patients 
typically result from assaults, traffic accidents, and falls. ${ }^{50}$ Those who have severe alcoholism may not present at the ED as often as occasional binge drinkers after a head injury. Chronic alcohol abusers are often brought to the ED by emergency medical services, indicating a more severe trauma. This may partially explain why chronic alcohol abuse was associated with increased risk for traumatic lesions but alcohol intoxication was not.

The incidence of acute traumatic lesions is much higher in patients with moderate to severe TBI, but it is possible to suffer a severe TBI without intracranial trauma visible on CT. CT underestimates many intracranial nonhemorrhagic lesions, especially DAI. ${ }^{41}$ The decades-old approach of classifying TBI severity based on the GCS could be improved by considering neuroimaging findings. The GCS is often supplemented by the clinical assessment of PTA and LOC, but both are prone to confounding factors. An injury severity classification system that incorporates neuroimaging findings could improve outcome prediction, resource allocation, and patient stratification in clinical trials. ${ }^{34}$

The present study has important limitations. First, the clinical variables were collected retrospectively from hospital records and hence some relevant information was missing. This may have introduced bias into our estimation of the relationship between patient and injury characteristics and CT findings. Second, the decision to order a head CT scan was left to the on-call ED physician's clinical judgment. This usual care methodology probably resulted in some patients undergoing CT scanning that would not have been needed according to the Scandinavian guidelines. ${ }^{22}$ Also, we might have missed some patients who should have undergone a CT scan but who were discharged without imaging (although the results suggest that a fairly liberal use of CT scanning was present over the study period).

Third, although the Scandinavian guidelines were used in the ED, these were probably not followed consistently. We do not have data in patients who did not undergo head CT scanning. The percentages of patients with MTBI with specific pathologies are an approximation because they do not include the subgroup of patients who were not triaged for CT. Some people with the mildest form of an MTBI probably did not undergo scanning; thus the rate of abnormalities in the MTBI group is likely higher than in the total population of those presenting to the ED (and, of course, that rate does not apply to those who do not present to the ED). It is probable that the number of CT-positive injuries would be smaller among patients with mild head trauma for whom a head CT scan was not performed.

Fourth, in our sample, 1 in 4 (776 patients [25.7\%]) did not have clearly documented clinical signs or symptoms of TBI in their medical records, which might reflect the absence of those signs, incomplete documentation, or both. Fifth, our sample contained a small number of patients who were classified as having sustained an MTBI, even though they had a GCS score < 13. In this group, low GCS score probably resulted from intoxication, medications, or other medical conditions. There is a possibility that the injury of some of these cases was incorrectly classified. Finally, all CT scans were analyzed and systematically coded by 2 neuroradiologists (A.B. and A.K.) using a structured and detailed case report form designed for this study, but we did not conduct a study related to the intrarater or interrater reliability of this case report form.

The reliability of CT findings may be limited by the subjective nature of the visual interpretations, by the qualitative nature of reporting, ${ }^{20}$ as well as by the experience and training of the reader (e.g., ED physician, radiologist, or neuroradiologist).${ }^{14,30}$ In our study, the scans were coded by 2 experienced neuroradiologists. In prior studies, interobserver reproducibility was good even among multiple readers with varying backgrounds when interpreting CT imaging features of TBI. ${ }^{6,14}$ Some studies have reported poorer interobserver agreement, but it seems that major findings are seldom missed. ${ }^{30}$ Overall, the discrepancy rate is low $(0.8 \%$; $95 \%$ CI $0.4 \%-1.6 \%)$ in head CT scans. ${ }^{64} \mathrm{Fu}-$ ture research could examine both intrarater and interrater reliability of this coding system.

Approximately 2 of 3 patients underwent CT scanning within the first 24 hours after injury. On the other hand, 1 of 4 patients underwent scanning $>48$ hours after injury. The temporal trends on how well certain traumatic lesions are visible on brain CT scans should be noted. Acute imaging (performed in the first hours after injury) can result in false negative scans; for example, some contusions do not demarcate as early as others. Furthermore, with delayed scanning (done days after injury), some minor subarachnoid hemorrhages can be missed because these lesions have already been reabsorbed. These CT-related limitations should be kept in mind when interpreting our findings.

The anatomical characteristics of a child's brain might make it more susceptible than the adult brain to certain types of injuries following head trauma. The head is larger in proportion to the body surface area, and stability is dependent on the ligamentous rather than bony structure. Subdural and subarachnoid hemorrhages were the most common intracranial lesions in the current study. The assessment of pediatric patients with head trauma is different than that of adults. Even in the pediatric population, the mainstay of imaging is $\mathrm{CT}$, but the significant radiation exposure must be considered. It is possible that some of the pediatric patients with TBI at our hospital had MRI as their first imaging study.

In this study, there was a large amount of missing data in the medical records on PTA, LOC, and GCS scores, which are part of the foundation of TBI diagnosis. These findings highlight the importance of a thorough medical history, focusing on the injury mechanism and confounding factors as well as a careful neurological examination that includes GCS score, mental state, and PTA measurements. The presence of PTA was noted much more often in patients with MTBI than in patients with more severe TBI. Often patients with moderate and severe TBIs have additional injuries that dominate clinical attention or they are unconscious at arrival and only progress to PTA after being transferred from the ED. There also might be a tendency for some physicians to document more specific injury criteria following MTBI, especially in patients with isolated head trauma, and to document fewer criteria in ED situations when the person has an obvious moderate or severe TBI. Finally, the study examined only patients with MTBI who presented to an ED. Rates of CT abnormalities in patients who do not seek acute care at an ED are not known. 


\section{Conclusions}

Approximately 1 in 6 patients who present to the ED with suspected or confirmed MTBI will have a CDE trauma-related intracranial abnormality on day-of-injury CT scan. The frequency of CT findings is much lower than in patients with moderate to severe TBI, but the type and location of lesions is very similar. Clinicians and researchers should also be aware that within the spectrum of MTBI, patient demographic variables (older age and male sex), preinjury exposures (alcohol abuse, but not preexisting brain lesions), mechanism of injury (falls and being struck by a motor vehicle), and reduced consciousness following injury (GCS score < 15) are all associated with an increased incidence of intracranial abnormality. Further research is needed to translate this knowledge into refined MTBI clinical stratifications and prognostics.

\section{References}

1. Borczuk P: Predictors of intracranial injury in patients with mild head trauma. Ann Emerg Med 25:731-736, 1995

2. Borgaro SR, Prigatano GP, Kwasnica C, Rexer JL: Cognitive and affective sequelae in complicated and uncomplicated mild traumatic brain injury. Brain Inj 17:189-198, 2003

3. Carroll LJ, Cassidy JD, Holm L, Kraus J, Coronado VG: Methodological issues and research recommendations for mild traumatic brain injury: the WHO Collaborating Centre Task Force on Mild Traumatic Brain Injury. J Rehabil Med 36 (43 Suppl):113-125, 2004

4. Cassidy JD, Cancelliere C, Carroll LJ, Côté P, Hincapié CA, Holm LW, et al: Systematic review of self-reported prognosis in adults after mild traumatic brain injury: results of the International Collaboration on Mild Traumatic Brain Injury Prognosis. Arch Phys Med Rehabil 95 (3 Suppl):S132S151, 2014

5. Chan V, Zagorski B, Parsons D, Colantonio A: Older adults with acquired brain injury: a population based study. BMC Geriatr 13:97, 2013

6. Chun KA, Manley GT, Stiver SI, Aiken AH, Phan N, Wang $\mathrm{V}$, et al: Interobserver variability in the assessment of CT imaging features of traumatic brain injury. J Neurotrauma 27:325-330, 2010

7. Coronado VG, Thomas KE, Sattin RW, Johnson RL: The CDC traumatic brain injury surveillance system: characteristics of persons aged 65 years and older hospitalized with a TBI. J Head Trauma Rehabil 20:215-228, 2005

8. Dams-O'Connor K, Gibbons LE, Landau A, Larson EB, Crane PK: Health problems precede traumatic brain injury in older adults. J Am Geriatr Soc 64:844-848, 2016

9. Daneshvar DH, Nowinski CJ, McKee AC, Cantu RC: The epidemiology of sport-related concussion. Clin Sports Med 30:1-17, 2011

10. Duhaime AC, Gean AD, Haacke EM, Hicks R, Wintermark $\mathrm{M}$, Mukherjee $\mathrm{P}$, et al: Common data elements in radiologic imaging of traumatic brain injury. Arch Phys Med Rehabil 91:1661-1666, 2010

11. Dunham CM, Hoffman DA, Huang GS, Omert LA, Gemmel DJ, Merrell R: Traumatic intracranial hemorrhage correlates with preinjury brain atrophy, but not with antithrombotic agent use: a retrospective study. PLoS One 9:e109473, 2014

12. Easter JS, Haukoos JS, Claud J, Wilbur L, Hagstrom MT, Cantrill S, et al: Traumatic intracranial injury in intoxicated patients with minor head trauma. Acad Emerg Med 20:753760, 2013

13. Easter JS, Haukoos JS, Meehan WP, Novack V, Edlow JA: Will neuroimaging reveal a severe intracranial injury in this adult with minor head trauma? The rational clinical examina- tion systematic review. JAMA 314:2672-2681, 2015 (Erratum in JAMA 317:2021, 2017)

14. Erly WK, Berger WG, Krupinski E, Seeger JF, Guisto JA: Radiology resident evaluation of head CT scan orders in the emergency department. AJNR Am J Neuroradiol 23:103107,2002

15. Feigin VL, Theadom A, Barker-Collo S, Starkey NJ, McPherson K, Kahan M, et al: Incidence of traumatic brain injury in New Zealand: a population-based study. Lancet Neurol 12:53-64, 2013

16. Haacke EM, Duhaime AC, Gean AD, Riedy G, Wintermark $\mathrm{M}$, Mukherjee $\mathrm{P}$, et al: Common data elements in radiologic imaging of traumatic brain injury. J Magn Reson Imaging 32:516-543, 2010

17. Haydel MJ, Preston CA, Mills TJ, Luber S, Blaudeau E, DeBlieux PM: Indications for computed tomography in patients with minor head injury. N Engl J Med 343:100-105, 2000

18. Hoge CW, McGurk D, Thomas JL, Cox AL, Engel CC, Castro CA: Mild traumatic brain injury in U.S. soldiers returning from Iraq. N Engl J Med 358:453-463, 2008

19. Holm L, Cassidy JD, Carroll LJ, Borg J: Summary of the WHO collaborating centre for neurotrauma task force on mild traumatic brain injury. J Rehabil Med 37:137-141, 2005

20. Huff JS, Jahar S: Differences in interpretation of cranial computed tomography in ED traumatic brain injury patients by expert neuroradiologists. Am J Emerg Med 32:606-608, 2014

21. Ibañez J, Arikan F, Pedraza S, Sánchez E, Poca MA, Rodriguez D, et al: Reliability of clinical guidelines in the detection of patients at risk following mild head injury: results of a prospective study. J Neurosurg 100:825-834, 2004

22. Ingebrigtsen $T$, Romner B, Kock-Jensen C: Scandinavian guidelines for initial management of minimal, mild, and moderate head injuries. J Trauma 48:760-766, 2000

23. Iverson GL: Complicated vs uncomplicated mild traumatic brain injury: acute neuropsychological outcome. Brain Inj 20:1335-1344, 2006

24. Iverson GL, Lange RT, Wäljas M, Liimatainen S, Dastidar P, Hartikainen KM, et al: Outcome from complicated versus uncomplicated mild traumatic brain injury. Rehabil Res Pract 2012:415740, 2012

25. Iverson GL, Lovell MR, Smith S, Franzen MD: Prevalence of abnormal CT-scans following mild head injury. Brain Inj 14:1057-1061, 2000

26. Jagoda AS, Bazarian JJ, Bruns JJ Jr, Cantrill SV, Gean AD, Howard PK, et al: Clinical policy: neuroimaging and decisionmaking in adult mild traumatic brain injury in the acute setting. Ann Emerg Med 52:714-748, 2008

27. Jeret JS, Mandell M, Anziska B, Lipitz M, Vilceus AP, Ware JA, et al: Clinical predictors of abnormality disclosed by computed tomography after mild head trauma. Neurosurgery 32:9-16, 1993

28. Koskinen S, Alaranta H: Traumatic brain injury in Finland 1991-2005: a nationwide register study of hospitalized and fatal TBI. Brain Inj 22:205-214, 2008

29. Kurca E, Sivák S, Kucera P: Impaired cognitive functions in mild traumatic brain injury patients with normal and pathologic magnetic resonance imaging. Neuroradiology 48:661-669, 2006

30. Laalo JP, Kurki TJ, Sonninen PH, Tenovuo OS: Reliability of diagnosis of traumatic brain injury by computed tomography in the acute phase. J Neurotrauma 26:2169-2178, 2009

31. Lee H, Wintermark M, Gean AD, Ghajar J, Manley GT, Mukherjee P: Focal lesions in acute mild traumatic brain injury and neurocognitive outcome: CT versus 3T MRI. J Neurotrauma 25:1049-1056, 2008

32. Lingsma HF, Roozenbeek B, Steyerberg EW, Murray GD, Maas AIR: Early prognosis in traumatic brain injury: from prophecies to predictions. Lancet Neurol 9:543-554, 2010

33. Livingston DH, Loder PA, Koziol J, Hunt CD: The use of CT 
scanning to triage patients requiring admission following minimal head injury. J Trauma 31:483-489, 1991

34. Maas AIR, Harrison-Felix CL, Menon D, Adelson PD, Balkin T, Bullock R, et al: Standardizing data collection in traumatic brain injury. J Neurotrauma 28:177-187, 2011

35. Maas AIR, Menon DK, Steyerberg EW, Citerio G, Lecky F, Manley GT, et al: Collaborative European NeuroTrauma Effectiveness Research in Traumatic Brain Injury (CENTERTBI): a prospective longitudinal observational study. Neurosurgery 76:67-80, 2015

36. Maas AI, Stocchetti N, Bullock R: Moderate and severe traumatic brain injury in adults. Lancet Neurol 7:728-741, 2008

37. McCauley SR, Boake C, Levin HS, Contant CF, Song JX: Postconcussional disorder following mild to moderate traumatic brain injury: anxiety, depression, and social support as risk factors and comorbidities. J Clin Exp Neuropsychol 23:792-808, 2001

38. Moore MM, Pasquale MD, Badellino M: Impact of age and anticoagulation: need for neurosurgical intervention in trauma patients with mild traumatic brain injury. J Trauma Acute Care Surg 73:126-130, 2012

39. Mower WR, Hoffman JR, Herbert M, Wolfson AB, Pollack CV Jr, Zucker MI: Developing a decision instrument to guide computed tomographic imaging of blunt head injury patients. J Trauma 59:954-959, 2005

40. National Institute for Health and Clinical Excellence: Head injury: assessment and early management. National Institute for Health and Clinical Excellence. (https://www.nice.org. uk/guidance/cg176) [Accessed September 11, 2017]

41. Ono K, Wada K, Takahara T, Shirotani T: Indications for computed tomography in patients with mild head injury. Neurol Med Chir (Tokyo) 47:291-298, 2007

42. Pandor A, Harnan S, Goodacre S, Pickering A, Fitzgerald P, Rees A: Diagnostic accuracy of clinical characteristics for identifying CT abnormality after minor brain injury: a systematic review and meta-analysis. J Neurotrauma 29:707718, 2012

43. Panenka WJ, Lange RT, Bouix S, Shewchuk JR, Heran MKS, Brubacher JR, et al: Neuropsychological outcome and diffusion tensor imaging in complicated versus uncomplicated mild traumatic brain injury. PLoS One 10:e0122746, 2015

44. Parry-Jones BL, Vaughan FL, Miles Cox W: Traumatic brain injury and substance misuse: a systematic review of prevalence and outcomes research (1994-2004). Neuropsychol Rehabil 16:537-560, 2006

45. Raj R, Siironen J, Skrifvars MB, Hernesniemi J, Kivisaari R: Predicting outcome in traumatic brain injury: development of a novel computerized tomography classification system (Helsinki computerized tomography score). Neurosurgery 75:632-647, 2014

46. Rathlev NK, Medzon R, Lowery D, Pollack C, Bracken M, Barest G, et al: Intracranial pathology in elders with blunt head trauma. Acad Emerg Med 13:302-307, 2006

47. Roozenbeek B, Maas AIR, Menon DK: Changing patterns in the epidemiology of traumatic brain injury. Nat Rev Neurol 9:231-236, 2013

48. Saatman KE, Duhaime AC, Bullock R, Maas AIR, Valadka A, Manley GT: Classification of traumatic brain injury for targeted therapies. J Neurotrauma 25:719-738, 2008

49. Saboori M, Ahmadi J, Farajzadegan Z: Indications for brain CT scan in patients with minor head injury. Clin Neurol Neurosurg 109:399-405, 2007

50. Savola O, Niemelä O, Hillbom M: Alcohol intake and the pattern of trauma in young adults and working aged people admitted after trauma. Alcohol Alcohol 40:269-273, 2005

51. Silverberg ND, Gardner AJ, Brubacher JR, Panenka WJ, Li JJ, Iverson GL: Systematic review of multivariable prognostic models for mild traumatic brain injury. J Neurotrauma 32:517-526, 2015
52. Smits M, Dippel DWJ, de Haan GG, Dekker HM, Vos PE, Kool DR, et al: External validation of the Canadian CT Head Rule and the New Orleans Criteria for CT scanning in patients with minor head injury. JAMA 294:1519-1525, 2005

53. Stein SC, Ross SE: Mild head injury: a plea for routine early CT scanning. J Trauma 33:11-13, 1992

54. Stiell IG, Clement CM, Rowe BH, Schull MJ, Brison R, Cass D, et al: Comparison of the Canadian CT Head Rule and the New Orleans Criteria in patients with minor head injury. JAMA 294:1511-1518, 2005

55. Stiell IG, Wells GA, Vandemheen K, Clement C, Lesiuk H, Laupacis A, et al: The Canadian CT Head Rule for patients with minor head injury. Lancet 357:1391-1396, 2001

56. Stulemeijer M, van der Werf S, Borm GF, Vos PE: Early prediction of favourable recovery 6 months after mild traumatic brain injury. J Neurol Neurosurg Psychiatry 79:936-942, 2008

57. Styrke J, Stålnacke BM, Sojka P, Björnstig U: Traumatic brain injuries in a well-defined population: epidemiological aspects and severity. J Neurotrauma 24:1425-1436, 2007

58. Temkin NR, Machamer JE, Dikmen SS: Correlates of functional status 3-5 years after traumatic brain injury with CT abnormalities. J Neurotrauma 20:229-241, 2003

59. Thiruppathy SP, Muthukumar N: Mild head injury: revisited. Acta Neurochir (Wien) 146:1075-1082, 2004

60. Thompson HJ, McCormick WC, Kagan SH: Traumatic brain injury in older adults: epidemiology, outcomes, and future implications. J Am Geriatr Soc 54:1590-1595, 2006

61. Undén J, Ingebrigtsen T, Romner B: Scandinavian guidelines for initial management of minimal, mild and moderate head injuries in adults: an evidence and consensus-based update. BMC Med 11:50, 2013

62. van der Naalt J, Hew JM, van Zomeren AH, Sluiter WJ, Minderhoud JM: Computed tomography and magnetic resonance imaging in mild to moderate head injury: early and late imaging related to outcome. Ann Neurol 46:70-78, 1999

63. Williams DH, Levin HS, Eisenberg HM: Mild head injury classification. Neurosurgery 27:422-428, 1990

64. Wu MZ, McInnes MD, Macdonald DB, Kielar AZ, Duigenan S: CT in adults: systematic review and meta-analysis of interpretation discrepancy rates. Radiology 270:717-735, 2014

65. Yuh EL, Mukherjee P, Lingsma HF, Yue JK, Ferguson AR, Gordon WA, et al: Magnetic resonance imaging improves 3 -month outcome prediction in mild traumatic brain injury. Ann Neurol 73:224-235, 2013

\section{Disclosures}

Professor Iverson is a consultant for NeuroHealth Research and Rehabilitation, Inc. and NeuroHealth, LLC.

\section{Author Contributions}

Conception and design: Isokuortti, Iverson, Silverberg, Luoto. Acquisition of data: Isokuortti, Brander, Luoto. Analysis and interpretation of data: Isokuortti, Silverberg, Kataja, Brander, Luoto. Drafting the article: all authors. Critically revising the article: all authors. Reviewed submitted version of manuscript: Isokuortti, Iverson, Silverberg, Kataja, Öhman, Luoto. Approved the final version of the manuscript on behalf of all authors: Isokuortti. Statistical analysis: Isokuortti, Silverberg. Administrative/ technical/material support: Isokuortti, Kataja, Brander. Study supervision: Luoto.

\section{Correspondence}

Harri Isokuortti: University of Tampere, Finland. harri. isokuortti@gmail.com. 